\title{
Highly frequent PIK3CA amplification is associated with poor prognosis in gastric cancer
}

Jing Shi ${ }^{1 \dagger}$, Demao Yao ${ }^{2 \dagger}$, Wei Liư ${ }^{1}$, Na Wang ${ }^{1}$, Hongjun Lv' ${ }^{1}$ Guanjun Zhang ${ }^{3}$, Meiju Ji', Li Xu', Nongyue He${ }^{4}$, Bingyin Shi ${ }^{1}$ and Peng Hou ${ }^{1 *}$

\begin{abstract}
Background: The phosphoinositide 3-kinase (PI3K)/Akt pathway plays a fundamental role in cell proliferation and survival in human tumorigenesis, including gastric cancer. PIK3CA mutations and amplification are two major causes of overactivation of this pathway in human cancers. However, until this work, there was no sound investigation on the association of PIK3CA mutations and amplification with clinical outcome in gastric cancer, particularly the latter.

Methods: Using direct sequencing and real-time quantitative PCR, we examined PIK3CA mutations and amplification, and their association with clinicopathological characteristics and clinical outcome of gastric cancer patients.

Results: PIK3CA mutations and amplification were found in 8/113 (7.1\%) and 88/131 (67\%) gastric cancer patients, respectively. PIK3CA amplification was closely associated with increased phosphorylated Akt (p-Akt) level. No relationship was found between PIK3CA mutations and clinicopathological characteristics and clinical outcome in gastric cancer. PIK3CA amplification was significantly positively associated with cancer-related death. Importantly, Kaplan-Meier survival curves revealed that the patients with PIK3CA amplification had significantly shorter survival times than the patients without PIK3CA amplification.

Conclusions: Our data showed that PIK3CA mutations were not common, but its amplification was very common in gastric cancer and may be a major mechanism in activating the PI3K/Akt pathway in gastric cancer. Importantly, Kaplan-Meier survival curves revealed that PIK3CA amplification was significantly positively associated with poor survival of gastric cancer patients. Collectively, the PI3K/Akt signaling pathway may be an effective therapeutic target in gastric cancer.
\end{abstract}

Keywords: Gastric cancer, PI3K/Akt pathway, PIK3CA mutations, PIK3CA amplification, Poor survival

\section{Background}

Gastric cancer is highly prevalent in Asia, particularly China, and is one of the leading cause of cancer-related death worldwide [1]. The histological classifications of gastric cancer involve two distinct types, intestinal and diffuse [2]. Although recent diagnostic and therapeutic advances have provided excellent survival for patients with early gastric cancer, the gastric cancer is usually diagnosed at an advanced stage and the prognosis is still poor [3], reflecting limited advances in our understanding

\footnotetext{
* Correspondence: phou@mail.xjtu.edu.cn

+ Contributed equally

'Department of Endocrinology, The First Affiliated Hospital of Xi'an Jiaotong University School of Medicine, Xi'an 710061, the People's Republic of China Full list of author information is available at the end of the article
}

of the pathogenesis of this disease and the molecular events that contributed to its development. A better understanding of the molecular mechanisms of gastric cancer may lead to new diagnostic, therapeutic and preventive approaches to this disease.

Gastric cancer is chronic proliferative disease characterized by multiple genetic and epigenetic events [4-6]. The aberrant signaling of major pathways is involved in this process, including phosphoinositide 3-kinase (PI3K)/Akt pathway, which plays a fundamental role in cell proliferation and survival in gastric tumorigenesis [7-9]. A key step in the signaling of PI3K/Akt pathway is the generation of phosphatidylinositol-3,4,5-trisphosphate (PIP3) catalyzed by PI3K. PI3K is composed of heterodimers of a p 85 regulatory subunit and one of the

\section{Biomed Central}


several p110 catalytic subunits. Among several isoforms of the catalytic subunits, only the $\alpha$-type, PIK3CA, has been shown to harbor oncogenic mutations in human cancer [10-12], including gastric cancer [13-15], implying an important role of PIK3CA mutations in gastric carcinogenesis. In addition to mutations, genomic amplification of $P I K 3 C A$ has been reported in various human cancers, including ovarian cancer, cervical cancer, thyroid cancer, and non-small cell lung cancer (NSCLC) [16-19]. Increased copy number of PIK3CA was closely associated with elevated mRNA or protein expression [16-18]. Importantly, PIK3CA overexpression caused by gene amplification increased PI3-kinase activity and phosphorylated Akt level, which was associated with aberrant cell proliferation and apoptosis, both of which are directly linked to tumorigenesis $[16,17,20]$.

In the present study, we analyzed a large cohort of clinically well-characterized gastric cancers for the presence of mutations in the exons 9 and 20 of PIK3CA gene by direct sequencing and PIK3CA amplification by real-time quantitative PCR, and correlated the presence of PIK3CA mutations and amplification with clinicopathological characteristics and clinical outcome of gastric cancer patients.

\section{Methods}

\section{Clinical samples}

With the institutional review board approval, a total of 131 paraffin-embedded gastric cancer tissues were randomly obtained from the First Affiliated Hospital of Xi'an Jiaotong University School of Medicine. The 37 normal controls from the patients with chronic gastritis who underwent endoscopic biopsy, were also obtained from the First Affiliated Hospital of Xi'an Jiaotong University School of Medicine. None of these patients received chemotherapy and radiotherapy before the surgery. Informed consent was obtained from each patient before the surgery. All of the samples were histologically examined by a pathologist at Department of Pathology of the Hospital to identify the clinicopathologic characteristics of the tumors, which are shown in Table 1.

\section{Tissues and DNA preparation}

Serial sections from each tumor sample were cut. One section $(5 \mu \mathrm{m})$ was stained by hematoxylin and eosin $(\mathrm{H} \& \mathrm{E})$ and a tumor representative tissue was marked by an expert surgical pathologist for gastric cancer. The next section $(8 \mu \mathrm{m})$ was deparaffinized and stained with hematoxylin. Tumor tissues were isolated by manual microdissection under an inverted microscope using the marked H\&E section for target tissue identification. Genomic DNA was extracted from isolated tissues as previously described [18]. Briefly, after a treatment for overnight at room temperature with xylene to remove pareffin, tissues were digested with $1 \%$ sodium dodecyl sulfate (SDS) and $0.5 \mathrm{mg} / \mathrm{ml}$ proteinase $\mathrm{K}$ at $48^{\circ} \mathrm{C}$ for $48 \mathrm{~h}$, with addition of several spiking aliquots of concentrated proteinase $\mathrm{K}$ to faciliate digestion. DNA was subsequently isolated using standard phenol/chloroform protocol, and was dissolved in distilled water and stored at $-80^{\circ} \mathrm{C}$ until use. Subsequent tissue sections $(5 \mu \mathrm{m})$ were prepared on 3-aminopropyltriethoxysilane (APTES) coated slides for immunohistochemical assay.

\section{Mutation analysis of PIK3CA gene}

In the present study, we selected exon 9 (for the regulatory helical domain) and exon 20 (for the kinase domain) of PIK3CA gene, two mutational hotspot regions, for mutation analysis as previous large-sclae analysis of PIK3CA mutations in various human cancers revealed that $>80 \%$ of the mutations clustered within these domains $[10,13,21,22]$. Genomic DNA was amplified by PCR using the amplifying and sequencing primers for these exons of PIK3CA gene as described previously [10]. The PCR was performed in a final volume of $20 \mu \mathrm{l}$ on a 96-well plate, which containing 60 ng genomic DNA, $16.6 \mathrm{mM}$ ammonium sulfate, $67 \mathrm{mM}$ Tris ( $\mathrm{pH} 8.8$ ), 5\% dimethylsulfoxide, $2 \mathrm{mM} \mathrm{MgCl}_{2}, 10 \mathrm{mM}$ 2-mercaptoethanol, $200 \mu \mathrm{M}$ of each deoxynucleotide triphosphate (dATP, dCTP, dGTP, and dTTP), $200 \mathrm{nM}$ of each primer (forward and reverse), and $0.6 \mathrm{U}$ platinum DNA Taq polymerase (Invitrogen Life Technologies, Inc., Gaithersburg, MD). Step-down PCR was run in a Thermal cycler (Bio-Rad Laboratories, Inc., CA) as follows: after a 4-min denaturing at $95^{\circ} \mathrm{C}$, the PCR was run with each temperature for $1 \mathrm{~min}$ at six step-down steps, for two cycles each. The denaturing temperature was $95^{\circ} \mathrm{C}$, and extension temperature was $72^{\circ} \mathrm{C}$ for each step, with the annealing temperature of $66^{\circ} \mathrm{C}, 64^{\circ} \mathrm{C}, 62^{\circ} \mathrm{C}, 60^{\circ} \mathrm{C}, 58^{\circ} \mathrm{C}$, and $56^{\circ} \mathrm{C}$ from the first to the last step. The PCR was finally run at $95^{\circ} \mathrm{C}, 56^{\circ} \mathrm{C}$, and $72^{\circ} \mathrm{C}$ each for $1 \mathrm{~min}$ for 35 cycles, followed by an elongation at $72^{\circ} \mathrm{C}$ for $5 \mathrm{~min}$. The PCR products were electrophoresed on a $1.2 \%$ agarose gel and visualized under UV illumination using an ethidium bromide stain. The direct sequencing was performed to analyze PIK3CA mutations on an ABI PRISM 3700 DNA Analyzer (Applied Biosystems) at the sequencing core of Beijing Genomics Institute (BGI, Beijing).

\section{Copy number analysis of PIK3CA gene with real-time quantitative PCR}

We analyzed the copy number of PIK3CA gene in 131 gastric cancer samples and 37 controls by real-time quantitative PCR technique on a CFX384 Thermal Cycler Dice $^{\mathrm{TM}}$ real-time PCR system (Bio-Rad Laboratories, Inc., CA) as described previously [23]. This method was well established and validated by florescence in situ hybridization (FISH) $[23,24]$, which has been widely used in the 
Table 1 Association of PIK3CA mutations and amplification with clinicopathologic variables

\begin{tabular}{|c|c|c|c|c|c|c|}
\hline \multirow[t]{2}{*}{ Variable } & \multicolumn{3}{|c|}{ PIK3CA mutations $(n=113)$} & \multicolumn{3}{|c|}{ PIK3CA amplification $(n=131)$} \\
\hline & Yes & No & $P$ & Yes & No & $P$ \\
\hline No.of patients & 8 & 105 & & 88 & 43 & \\
\hline \multicolumn{7}{|l|}{ Gender } \\
\hline Male & 5 & 82 & 0.57 & 68 & 34 & 0.82 \\
\hline Female & 3 & 23 & & 20 & 9 & \\
\hline \multicolumn{7}{|l|}{ Age, years } \\
\hline Mean & 55.5 & 59.1 & 0.47 & 58.6 & 61.4 & 0.25 \\
\hline SD & 19.8 & 12.7 & & 13.3 & 12.1 & \\
\hline \multicolumn{7}{|l|}{ Tumor localization } \\
\hline gastric cardia & 0 & 26 & 0.98 & 23 & 12 & 0.66 \\
\hline gastric body & 5 & 24 & & 22 & 12 & \\
\hline gastric antrum & 3 & 55 & & 43 & 19 & \\
\hline \multicolumn{7}{|l|}{ Tumor size $\left(\mathrm{cm}^{3}\right)$} \\
\hline$\leq 3$ & 3 & 35 & 0.68 & 29 & 14 & 0.88 \\
\hline $3-5$ & 3 & 35 & & 32 & 15 & \\
\hline$>5$ & 2 & 35 & & 27 & 14 & \\
\hline \multicolumn{7}{|l|}{ Differentiation } \\
\hline well/moderate & 1 & 44 & 0.21 & 33 & 23 & 0.08 \\
\hline poor/undifferentiation & 7 & 61 & & 55 & 20 & \\
\hline \multicolumn{7}{|l|}{ Tumor invasion } \\
\hline $\mathrm{T1}$ & 2 & 14 & 0.96 & 9 & 5 & 0.59 \\
\hline $\mathrm{T} 2$ & 0 & 17 & & 15 & 8 & \\
\hline T3 & 6 & 72 & & 62 & 30 & \\
\hline T4 & 0 & 2 & & 2 & 0 & \\
\hline \multicolumn{7}{|l|}{ TNM stage } \\
\hline 1 & 2 & 27 & 0.91 & 20 & 10 & 0.86 \\
\hline$\|$ & 1 & 14 & & 15 & 6 & \\
\hline III & 5 & 58 & & 49 & 25 & \\
\hline IV & 0 & 6 & & 4 & 2 & \\
\hline \multicolumn{7}{|l|}{ Residual tumor } \\
\hline Yes & 1 & 12 & 1.00 & 12 & 2 & 0.10 \\
\hline No & 7 & 93 & & 76 & 41 & \\
\hline \multicolumn{7}{|l|}{ Lymph node metastasis (LNM) } \\
\hline Yes & 5 & 65 & 1.00 & 57 & 24 & 0.32 \\
\hline No & 3 & 40 & & 31 & 19 & \\
\hline \multicolumn{7}{|l|}{ No. of LNM } \\
\hline No & 3 & 40 & 0.63 & 31 & 19 & 0.20 \\
\hline N1 (1-6) & 4 & 36 & & 32 & 16 & \\
\hline N2 (7-15) & 1 & 23 & & 20 & 7 & \\
\hline N3 $(\geq 16)$ & 0 & 6 & & 5 & 1 & \\
\hline \multicolumn{7}{|l|}{ Survival status } \\
\hline Dead & 3 & 53 & 0.73 & 51 & 15 & $0.01^{*}$ \\
\hline Alive & 5 & 52 & & 37 & 28 & \\
\hline
\end{tabular}


various human cancers [18,23-25]. Specific primers and TaqMan probes were designed using Primer Express 3.0 (Applied Biosystems) to amplify PIK3CA and $\beta$-actin genes as described previously [18]. Using a PCR protocol described previously [23], each sample was run in triplicate, and $\beta$-actin was run in parallel to standardize the input DNA. Standard curves were established using serial dilutions of normal leukocyte DNA with a quantity range of 3.75-60 ng per $2 \mu \mathrm{l}$. Copy gain (or amplification) of PIK3CA gene was defined by a copy number $\geq 4$.

\section{Immunohistostaining (IHS) of phosphorylated akt (p-akt)}

This procedure was pursued to investigate the level of $\mathrm{p}$ Akt in relation to PIK3CA copy gain in the tumor. Briefly, formaldehyde fixed, paraffin-embedded tissue sections $(5 \mu \mathrm{m})$ were deparaffinized and rehydrated in xylene and degradation alcohol. Antigen unmasking was performed by pretreatment of the slides in $0.01 \mathrm{M}$ citrate buffer ( $\mathrm{pH} 6.0)$ at $98^{\circ} \mathrm{C}$ for $15 \mathrm{~min}$ using a microwave oven. The slides were then cooled to room temperature on bench top for $20 \mathrm{~min}$. Endogenous peroxidase was cleaned by incubating the slides in 3\% hydrogen peroxide for $5 \mathrm{~min}$. After washed in $0.01 \mathrm{M} \mathrm{PBS} \mathrm{(pH} \mathrm{7.4),} \mathrm{the} \mathrm{sec-}$ tions were incubated for $10 \mathrm{~min}$ at room temperature with normal goat serum, followed by incubation with anti-p-Akt antibody (BS4007, Bioworld Technology, Inc., $\mathrm{MN}$ ) overnight at $4^{\circ} \mathrm{C}$. The sections were subsequently washed with PBS and incubated with biotinylated goat anti-rabbit IgG (SP9000, Zhongshan Goldenbridge, Beijing) and streptavidin-peroxidase complex, followed by reaction with diaminobenzidine and counterstaining with hematoxylin. Negative control was performed by omission of primary antibody. For positive control, we used samples from previously examined gastric cancer tissues positive for p-Akt. The level of p-Akt was scored in double-blinding way (i.e., without knowing the PIK3CA copy number of the case), and 0, 1, 2, 3 reprints negative, weak positive, positive, and strong positive, respectively.

\section{Statistical analysis}

The Mann-Whitney $U$ test was used to compare copy number of PIK3CA gene between gastric cancer and normal gastric samples. Correlation between PIK3CA mutations or amplification and clinicopathological characteristics was analyzed by Fisher's exact test or Pearson's Chi square test. The Mann-Whitney $U$ test was used for ordinal variables. Factors (PIK3CA mutations or amplification) associated with clinicopathological characteristics of tumor were assessed univariately using the SPSS statistical package (11.5, Chicago, IL, USA). Multivariate models were then developed that adjusted for the most important covariates, including tumor size, differentiation, tumor stage, lymph node metastasis and survival status. Survival length was determined from the day of primary tumor surgery to the day of death or last clinical follow-up. The Kaplan-Meier method was used for survival analysis grouping with PIK3CA mutations or amplification. Differences between curves were analyzed using the log-rank test. Multivariate Cox regression analysis was used to evaluate the effect of PIK3CA amplification on survival of independently of age, differentiation, lymph node metastasis, and TNM stage. All statistical analyses were performed using the SPSS statistical package (11.5, Chicago, IL, USA). $P$ values $<0.05$ were considered significant.

\section{Results}

\section{PIK3CA mutations and amplification in gastric cancer}

As the first step to understand the role of PIK3CA gene in gastric cancer, we sequenced exons 9 and 20 of this gene in a large cohort of gastric cancers. A total of 8 PIK $3 C A$ mutations $(7.1 \%)$ were found in the 113 gastric cancers. Of these, 3 mutations, including P539S, E542K and E545K, were in the exon 9, and 5 mutations, including H1048D, G1050S,W1057R,W1057C and I1062T, were in the exon 20. All mutations found were heterozygous missense single base substitutions (see Additional file 1: Figure S1). To analyze copy number of PIK3CA gene, real-time quantitative PCR assay was performed in the 131 gastric cancers and 37 normal controls. With a gene copy number of 4 or more defined as amplification, we found the incidence of PIK3CA amplification in gastric cancers was 67\% (88/131) in the present study, whereas no PIK3CA amplification was found in the 37 normal controls. Copy number of PIK3CA gene corresponding to each individual case of gastric cancers and normal gastric tissues is shown in Figure 1. Statistical analysis showed that copy number of PIK3CA gene in gastric cancers was significantly higher than normal gastric tissues $(P<0.0001)$.

To investigate the effect of PIK3CA amplification on the activity of PI3K/Akt signaling pathway, we randomly selected 13 gastric cancer samples with various PIK3CA copies and did immunohistostaining for p-Akt. As illustrated by the representative samples in Figure $2 \mathrm{~A}$, and all of selected 13 samples in Figure 2B, increased staining of p-Akt was seen with increased PIK3CA copies.

\section{Association of PIK3CA mutations and amplification with clinicopathological characteristics of gastric cancer} Because PIK3CA mutations and amplification, particularly highly frequent $P I K 3 C A$ amplification, was demonstrated in gastric cancer, the association of PIK3CA mutations and amplification with clinicopathological characteristics was analyzed in a large cohort of clinically well-characterized gastric cancers. As shown in Table 1, PIK3CA mutations and amplification, particularly the former, showed no relation to most of clinicopathological characteristics. PIK3CA amplification was significantly 


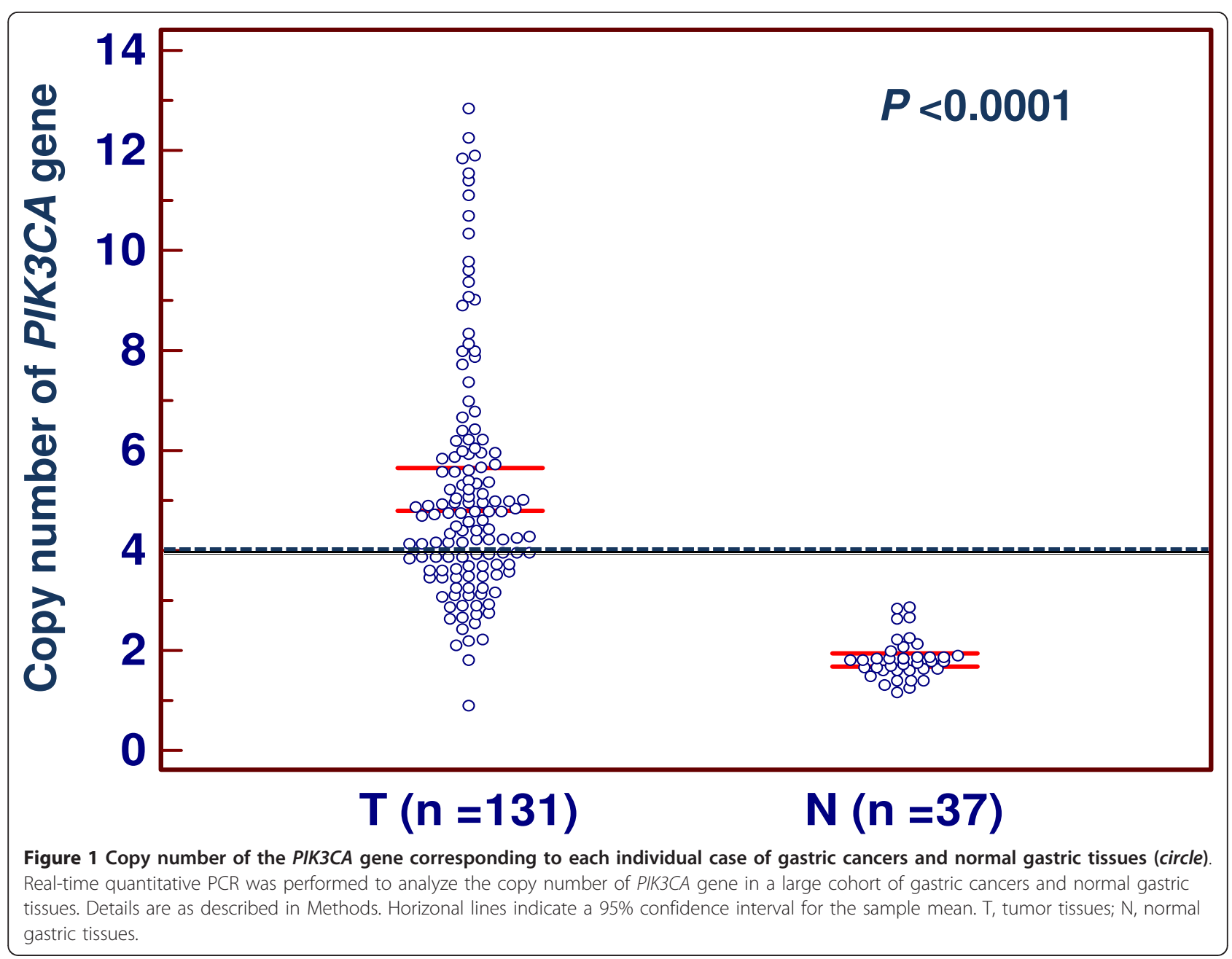

positively associated with cancer-related death $(P=0.01)$. Although no statistical significance was noted, there was a positive association of PIK3CA mutations and amplification with tumor differentiation (Table 1). Similarly, the univariate analysis also showed PIK3CA amplification was associated with a significantly increased risk of cancer-related death $(\mathrm{OR}=2.57,95 \% \mathrm{CI}=1.21-5.48 ; \mathrm{P}<$ $0.05)$, and there was a positive association of $P I K 3 C A$ mutations $(\mathrm{OR}=5.05,95 \% \mathrm{CI}=0.60-42.5)$ and PIK3CA amplification $(\mathrm{OR}=1.92,95 \% \mathrm{CI}=0.92-4.01)$ with tumor differentiation (see Additional file 1: Table S1). In order to assess the independent association of PIK3CA mutations and amplification with tumor size, tumor differentiation, tumor stage, lymph node metastasis and survival status, we conducted two multivariable logistic regressions (Table 2). Similar to univariate analysis, after adjustment, PIK3CA amplification was still significantly associated with higher mortality $(\mathrm{OR}=3.50,95 \% \mathrm{CI}=$ 1.36-9.00; $P<0.05$ ), and $P I K 3 C A$ mutations remained positively associated with tumor differentiation $(\mathrm{OR}=$ 5.53, 95\% CI $=0.65-47.4$ ) (Table 2).
Effect of PIK3CA mutations and amplification on poor survival in gastric cancer

The Kaplan-Meier estimator of the survivorship function was used to determine the effect of PIK3CA mutations and amplification on the survival of gastric cancer patients. The overall survival of gastric cancer patients with and without PIK3CA mutations/amplification was compared using the log-rank test. As shown in Additional file 1: Figure S2, PIK3CA mutations did not affect the overall prognosis of gastric cancer patients $(P=$ 0.44). However, the patients with $P I K 3 C A$ amplification had significantly shorter survival times than the patients without PIK3CA amplification (516.0 months vs. 758.4 months on average; $P=0.008)$.

Many evidences showed that residual tumor after surgery is an independent risk factor for gastric cancer patients. In the present study, indeed, the patients with residual tumor after surgery had significantly shorter survival times than the patients without residual tumor (343.2 months vs. 627.6 months on average; $P=0.002$ ) (Figure 3 ). Thus, we excluded the patients with residual 


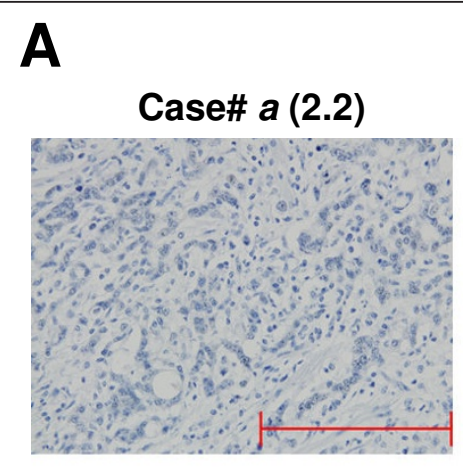

\section{Case\# $d(5.0)$}

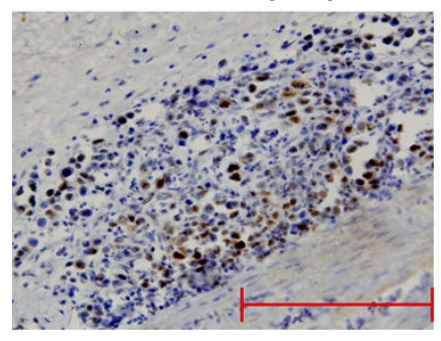

\section{Case\# $b(2.4)$}

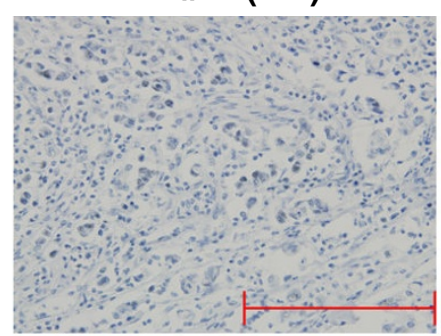

Case\# e (8.0)

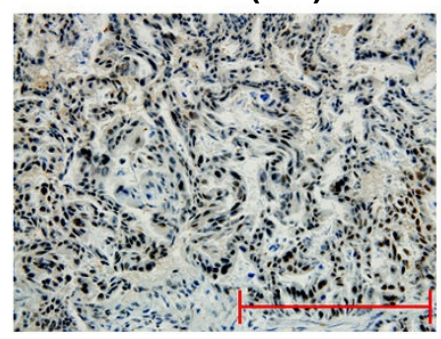

Case\# $c$ (2.8)

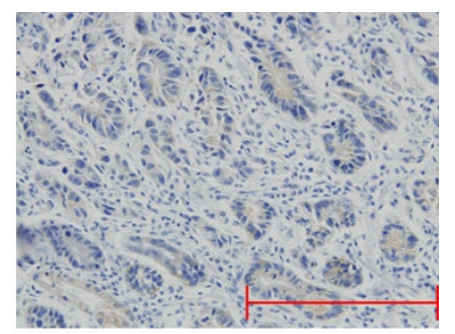

\section{Case\# $f(9.3)$}

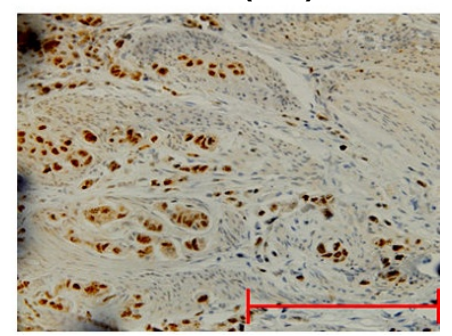

B

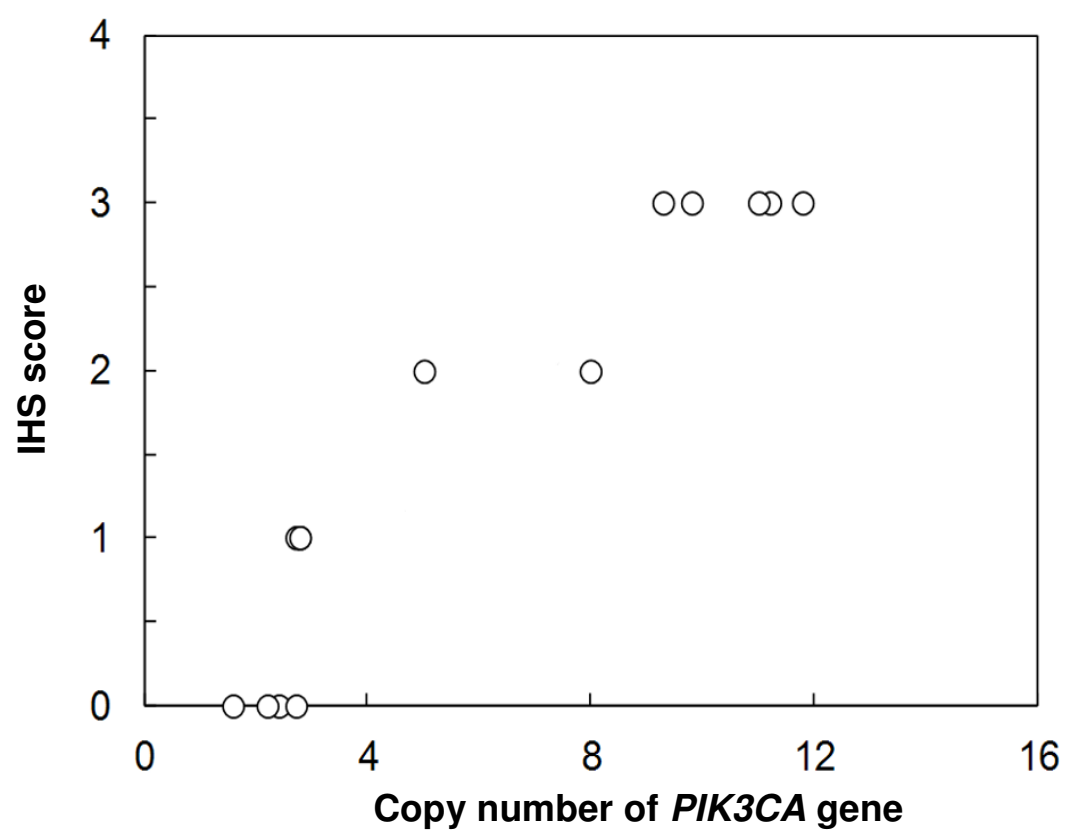

Figure 2 Immunohistostaining of phosphorylated Akt (p-Akt): correlation of PIK3CA copies with increased p-Akt level. (A) Representative samples of immunohistostaining on gastric cancer histologic slides using anti-p-Akt antibodies. Increasing extent of specific

staining (brown color) in association with increasing PIK3CA copies (number inside brackets). (B) Association of immunohistostaining (IHS) score of p-Akt with PIK3CA copies on 13 randomly selected gastric cancer samples. 
Table 2 PIK3CA mutations and amplification in gastric cancer-multivariable models assessing tumor size, differentiation, tumor stage, lymph node metastasis and survival status $\left(\mathrm{OR}^{\dagger}\right.$ and $\left.95 \% \mathrm{Cl}\right)$

\begin{tabular}{|c|c|c|}
\hline Factors & PIK3CA mutations $\left[\mathrm{OR}^{\dagger}(95 \% \mathrm{Cl})\right]$ & PIK3CA amplification $\left[\mathrm{OR}^{\dagger}(95 \% \mathrm{Cl})\right]$ \\
\hline$\overline{\text { Tumor size }^{1}}$ & $0.80(0.29-2.21)$ & $0.88(0.50-1.54)$ \\
\hline Differentiation ${ }^{2}$ & $5.53(0.65-47.4)$ & $1.85(0.86-4.02)$ \\
\hline Tumor stage ${ }^{3}$ & $1.19(0.33-4.35)$ & $0.60(0.31-1.17)$ \\
\hline Lymph node metastasis & $1.32(0.13-13.6)$ & $1.44(0.45-4.58)$ \\
\hline Survival status ${ }^{4}$ & $0.41(0.07-2.41)$ & $3.50(1.36-9.00)^{*}$ \\
\hline
\end{tabular}

* Significant at $P<0.05$

† OR: odds ratio with $95 \%$ confidence interval

${ }^{1}$ Tumor size ( $\leq 3 \mathrm{~cm} ;>3 \mathrm{~cm}$ and $\leq 5 \mathrm{~cm} ;>5$ )

${ }^{2}$ Differentiation (well or moderate; poor or no differentiation)

${ }^{3}$ Tumor stage (I; II; III; IV)

${ }^{4}$ Survival status (alive; dead)

tumor to explore the association of PIK3CA mutations and amplification with the survival of gastric cancer patients again. Similar to the findings in Additional file 1: Figure S2, PIK3CA mutations did not have any prognostic value for gastric cancer patients (Figure 4A). However, PIK3CA amplification significantly affected clinical outcomes of gastric cancer patients. The patients with PIK3CA amplification had significantly shorter survival times than the patients without PIK3CA amplification (540.0 months vs. 794.4 months on average; $P=0.03$ ) (Figure 4B). The data were stratified further according to the TNM tumor stage, because it is an independent risk

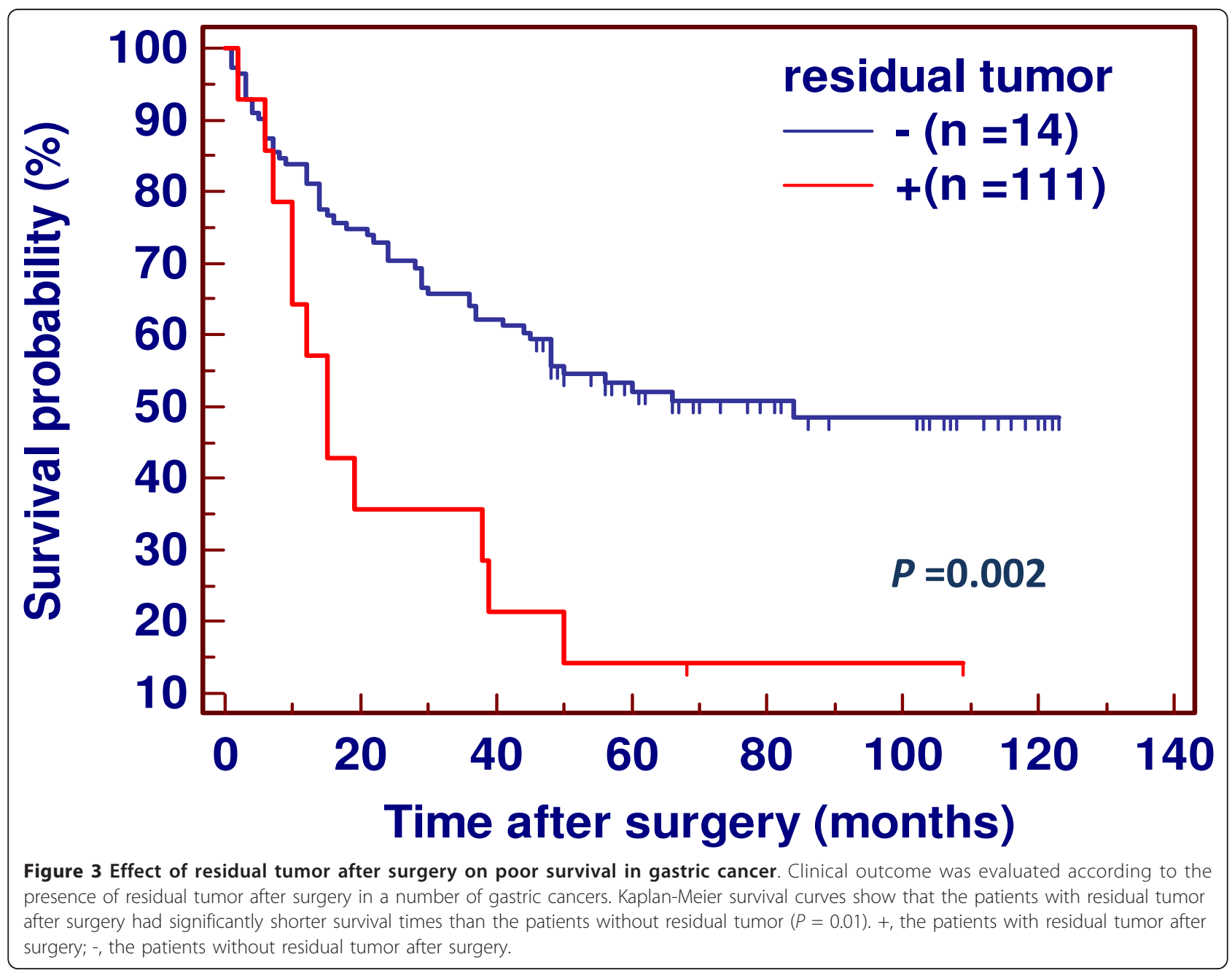



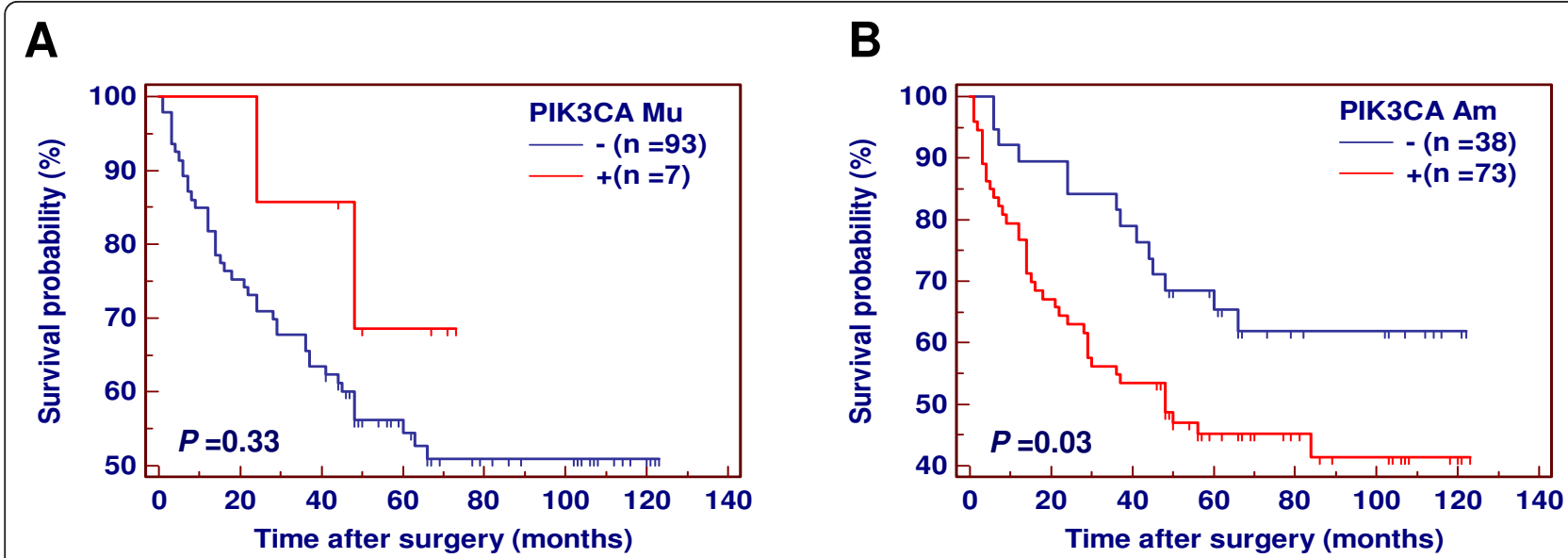

C
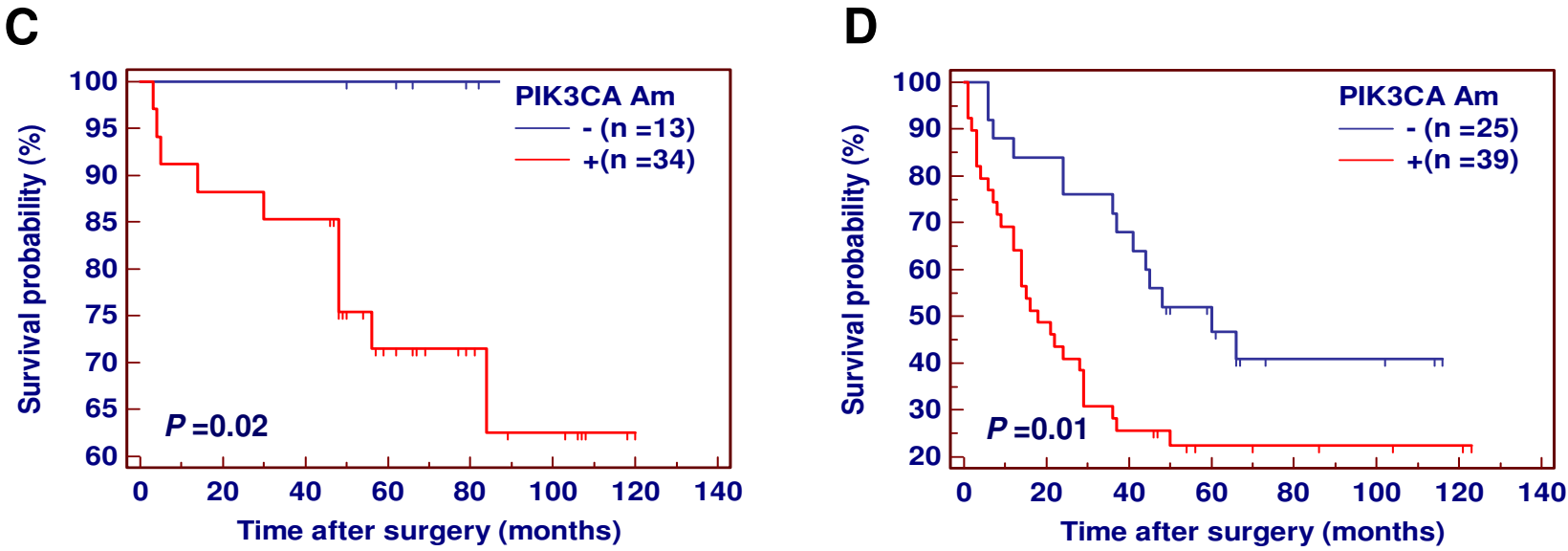

Figure 4 Association of PIK3CA mutations and amplification with clinical outcome in patients with gastric cancer. Kaplan-Meier analysis of survival was performed according to the presence of PIK3CA mutations or amplification in a large cohort of gastric cancers. (A) Kaplan-Meier survival curves show that PIK3CA mutations were not associated with poor survival of the patients. (B) The patients with PIK3CA amplification had poorer survival than the patients without PIK3CA amplification. (C) PIK3CA amplification was extremely significantly associated with poor survival in the patients who had early-stage tumors $(P=0.004)$. (D) PIK3CA amplification was marginally significantly associated with poor survival in the patients who had late-stage tumors $(P=0.06)$. PIK3CA Mu, PIK3CA mutations; PIK3CA Am, PIK3CA amplification; +, harboring PIK3CA mutations or amplification; -, the lack of PIK3CA mutations or amplification.

factor in gastric cancer patients. As shown in Figure 4C and 4D, PIK3CA amplification was significantly associated with poor survival whatever the patients who had early-stage tumors (stage I and II) or late-stage tumors (stage III and IV). Multivariate Cox regression analysis indicated that PIK3CA amplification is a predictor of poor prognosis for gastric cancer patients $(H R=2.59$, $95 \% \mathrm{CI}=1.39-4.82, P=0.003)$ as an independently variable with respect to age, differentiation, lymph node metastasis, and TNM stage (Table 3).

\section{Discussion}

It has been well documented that the PI3K/Akt pathway plays an important role in cancer-related functions of
Table 3 Multivariate Cox regression analysis of clinical variables on overall survival

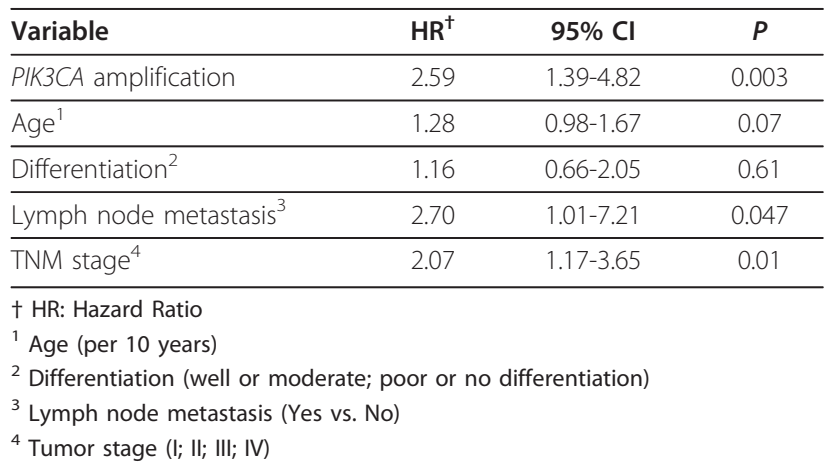


cell proliferation, catabolism, cell adhesion and apoptosis $[10,16,17,26,27]$, and it has a crucial role in the tumorigenesis and pathogenesis of many human cancers. The previous studies have shown that PIK3CA, as a subunit of PI3K, is frequently mutated in various human cancers, such as ovarian, thyroid cancer, breast, cervical cancers, and pituitary tumors $[10,12,13,16,17,21,28]$. However, our study showed that the most common activating PIK3CA mutations reported in other cancers were not frequent in gastric cancer. Therefore, the PIK3CA mutations may not be a common mechnaism in the activation of PI3K/Akt signaling pathway. Instead, our study demonstrated PIK3CA gene was highly amplified in gastric cancer. Genomic amplification, rather than gene mutations, may represent another major signature of neoplastic transformation and tumor progression [29]. Chromosome copy number abnormalities have been frequently identified in gastric cancer [30], including PIK3CA amplification [31].

Of particular interest was the PIK3CA amlification was closely associated with elevated p-Akt, suggesting that this genetic alteration could lead to oncogenic activation of PI3K/Akt signaling pathway and thus contributed to the malignant progression of gastric cancer. It was consistent with a previous study [31], which PIK3AC gene was aberrantly amplified, and mutually excluded with monallelic deletion of PTEN gene in gastric cancer, further supporting that $P I K 3 C A$ amplification, like PTEN loss, might contribute to gastric tumorigenesis through the activation of the PI3K/Akt pathway.

Given PIK3CA mutations and amplification play the critical role in gastric tumorigenesis, we investigated their clinical significances and prognostic values in a large cohort of gastric cancer patients who had known survival data. Out data showed that PIK3CA mutations were not associated with most of clinicopathological characteristics and clinical outcome in gastric cancer. One possibility is the limited number of PIK3CA mutations found in this study. However, PIK3CA amplification was associated with a significantly increased risk of cancer-related death, and positively associated tumor differentiation. Most noteworthy, PIK3CA amplification significantly affected the overall prognosis in gastric cancer whatever the patients who had early-stage or latestage tumors, suggesting that this genetic event plays an important role in the multistep process of gastric carcinogenesis. Taken together, PIK3CA amplification may be served as a potential prognostic marker for gastric cancer patients.

The prognostic markers may have another role in predicting and guiding the clinical treatment of cancer patients by allowing the identification of patients suited to current therapies. In this era of molecularly targeted therapy, inhibitors and antibodies targeting specific molecules are vigorously being developed, and some have been demonstrated to be effective in clinical settings, such as hematological malignancies [32] and nonsmall cell lung cancer (NSCLC) [33,34]. Of interest, some of these targeted drugs are more effective against the genetically altered cancerous form of the target, as illustrated by the activities of gefitinib and erlotinib against the mutated EGFR present in NSCLC $[33,34]$, and the activity of trastuzumab against breast cancer with amplified ErbB2 [35]. Mutations and amplification of certain kinases are involved in gastric tumorigenesis. However, only has trastuzumab, which is a monoclonal antibody targeting ErbB2, been recently approved as the first molecularly targetd drug against gastric cancer. The PI3K/Akt pathway is one of the most important signaling pathways in human carcinogenesis. In the present study, a high prevalence of PIK3CA amplification was found in gastric cancer, which was significantly associated with poor prognosis of gastric cancer patients. Importantly, PIK3CA amplification could aberrantly activate the PI3K/Akt signaling pathway. In addition, the drugs, such as mTOR and Akt inhibitors that target this signaling pathway, are being vigorously developed [36]. Thus, for some gastric cancer patients harbored oncogenic alterations within the PI3K/Akt signaling pathway, such as PIK3CA amplification, combination therapy with an mTOR or Akt inhibitor should be considered.

\section{Conclusions}

In summary, our data showed that PIK3CA mutations may not be frequent genetic event in gastric cancer, however, PIK3CA gene was highly amplified in gastric cancer. To our knowledge, the present study is the first to demonstrate that PIK3CA amplification was significantly associated with poor survival in gastric cancer. More importantly, PIK3CA amplification was closely associated with elevated p-Akt, suggesting that this genetic alteration may be a major mechanism in activating the PI3K/Akt signaling pathway, and contribute to gastric tumorigenesis. Thus, specific genotype-based targeting against the PI3K/Akt signaling pathway may be an effective therapeutic strategy for gastric cancer.

\section{Additional material}

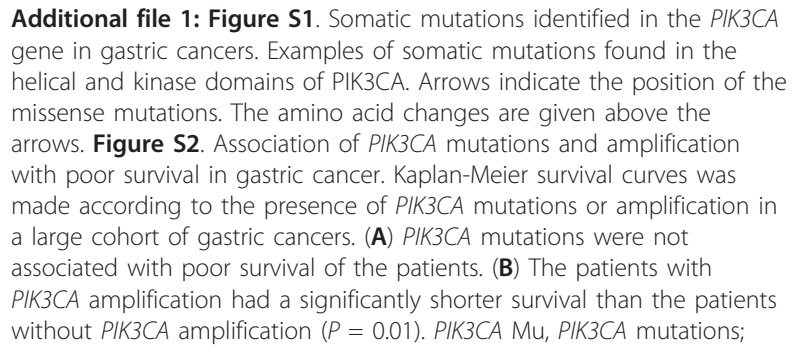

Additional file 1: Figure S1. Somatic mutations identified in the PIK3CA gene in gastric cancers. Examples of somatic mutations found in the helical and kinase domains of PIK3CA. Arrows indicate the position of the missense mutations. The amino acid changes are given above the arrows. Figure S2. Association of PIK3CA mutations and amplification with poor survival in gastric cancer. Kaplan-Meier survival curves was made according to the presence of PIK3CA mutations or amplification in a large cohort of gastric cancers. (A) PIK3CA mutations were not associated with poor survival of the patients. (B) The patients with PIK3CA amplification had a significantly shorter survival than the patients without PIK3CA amplification ( $P=0.01)$. PIK3CA Mu, PIK3CA mutations; 
PIK3CA Am, PIK3CA amplification; +, harboring PIK3CA mutations or amplification; -, the lack of PIK3CA mutations or amplification. Table S1. PIK3CA mutations and amplification in gastric cancer-univariate associations with clinicopathological features (OR+ and 95\% Cl).

\section{Acknowledgements}

This work was supported by the National Natural Science Foundation of China (No. 30901459 and 30973372) and the National Key Program for Developing Basic Research (No. 2010CB933903).

\section{Author details}

'Department of Endocrinology, The First Affiliated Hospital of Xi'an Jiaotong University School of Medicine, Xi'an 710061, the People's Republic of China. ${ }^{2}$ Department of Surgery, The First Affiliated Hospital of Xi'an Jiaotong University School of Medicine, Xi'an 710061, the People's Republic of China. ${ }^{3}$ Department of Pathology, The First Affiliated Hospital of Xi'an Jiaotong University School of Medicine, Xi'an 710061, the People's Republic of China. ${ }^{4}$ State Key Laboratory of Bioelectronics, Southeast University, Nanjing 210096, the People's Republic of China.

\section{Authors' contributions}

PH conceived and designed the experiments. JS, DY, WL, NW, HL, and LX performed the experiments. DY, YC, and $\mathrm{NH}$ collected the patient materials. $\mathrm{MJ}, \mathrm{NH}$, and $\mathrm{PH}$ analyzed the data. $\mathrm{HL}$ and $\mathrm{GZ}$ carried out the histopathological analysis. BS and $\mathrm{PH}$ contributed reagents/materials/analysis tools. JS and PH wrote the paper. All authors are in agreement with the content of the manuscript and this submission.

\section{Competing interests}

The authors declare that they have no competing interests.

Received: 4 October 2011 Accepted: 1 February 2012

Published: 1 February 2012

\section{References}

1. Jemal A, Siegel R, Ward E, Murray T, Xu J, Thun MJ: Cancer statistics, 2007. CA Cancer J Clin 2007, 57:43-66

2. Yuasa $Y$ : Control of gut differentiation and intestinal-type gastric carcinogenesis. Nat Rev Cancer 2003, 3:592-600.

3. Kim HJ, Karpeh MS: Surgical approaches and outcomes in the treatment of gastric cancer. Semin Radiat Oncol 2002, 12:162-169.

4. Yasui W, Oue N, Kuniyasu H, Ito R, Tahara E, Yokozaki H: Molecular diagnosis of gastric cancer: present and future. Gastric Cancer 2001, 4:113-121.

5. Yokozaki H, Yasui W, Tahara E: Genetic and epigenetic changes in stomach cancer. Int Rev Cytol 2001, 204:49-95

6. Yasui W, Oue N, Aung PP, Matsumura S, Shutoh M, Nakayama $\mathrm{H}$ : Molecular-pathological prognostic factors of gastric cancer: a review. Gastric Cancer 2005, 8:86-94.

7. Michl P, Downward J: Mechanisms of disease: PI3K/AKT signaling in gastrointestinal cancers. Z Gastroenterol 2005, 43:1133-1139.

8. Yu HG, Ai YW, Yu LL, Zhou XD, Liu J, Li JH, Xu XM, Liu S, Chen J, Liu F, Qi YL, Deng Q, Cao J, Liu SQ, Luo HS, Yu JP: Phosphoinositide 3-kinase/ Akt pathway plays an important role in chemoresistance of gastric cancer cells against etoposide and doxorubicin induced cell death. Int J Cancer 2008, 122:433-443.

9. Qu JL, Qu XJ, Zhao MF, Teng YE, Zhang Y, Hou KZ, Jiang YH, Yang XH, Liu YP: Gastric cancer exosomes promote tumour cell proliferation through PI3K/Akt and MAPK/ERK activation. Dig Liver Dis 2009, 41:875-880.

10. Samuels $Y$, Wang Z, Bardelli A, Silliman N, Ptak J, Szabo S, Yan H, Gazdar A, Powell SM, Riggins GJ, Willson JK, Markowitz S, Kinzler KW, Vogelstein B, Velculescu VE: High frequency of mutations of the PIK3CA gene in human cancers. Science 2004, 304:554.

11. Lee JW, Soung YH, Kim SY, Lee HW, Park WS, Nam SW, Kim SH, Lee JY, Yoo NJ, Lee SH: PIK3CA gene is frequently mutated in breast carcinomas and hepatocellular carcinomas. Oncogene 2005, 24:1477-1480.
12. Garcia-Rostan G, Costa AM, Pereira-Castro I, Salvatore G, Hernandez R, Hermsem MJ, Herrero A, Fusco A, Cameselle-Teijeiro J, Santoro M: Mutation of the PIK3CA gene in anaplastic thyroid cancer. Cancer Res 2005, 65:10199-10207.

13. Velho S, Oliveira C, Ferreira A, Ferreira AC, Suriano G, Schwartz $S$ Jr, Duval A Carneiro F, Machado JC, Hamelin R, Seruca R: The prevalence of PIK3CA mutations in gastric and colon cancer. Eur J Cancer 2005, 41:1649-1654.

14. Barbi S, Cataldo I, De Manzoni G, Bersani S, Lamba S, Mattuzzi S, Bardelli A Scarpa A: The analysis of PIK3CA mutations in gastric carcinoma and metanalysis of literature suggest that exon-selectivity is a signature of cancer type. J Exp Clin Cancer Res 2010, 29:32.

15. Corso G, Velho S, Paredes J, Pedrazzani C, Martins D, Milanezi F, Pascale V, Vindigni C, Pinheiro H, Leite M, Marrelli D, Sousa S, Carneiro F, Oliveira C, Roviello F, Seruca R: Oncogenic mutations in gastric cancer with microsatellite instability. Eur J Cancer 2011, 47:443-451.

16. Shayesteh L, Lu Y, Kuo WL, Baldocchi R, Godfrey T, Collins C, Pinkel D, Powell B, Mills GB, Gray JW: PIK3CA is implicated as an oncogene in ovarian cancer. Nat Genet 1999, 21:99-102.

17. Ma YY, Wei SJ, Lin YC, Lung JC, Chang TC, Whang-Peng J, Liu JM, Yang DM, Yang WK, Shen CY: PIK3CA as an oncogene in cervical cancer. Oncogene 2000, 19:2739-2744.

18. Hou P, Liu D, Shan Y, Hu S, Studeman K, Condouris S, Wang Y, Trink A, ElNaggar AK, Tallini G, Vasko V, Xing M: Genetic alterations and their relationship in the phosphatidylinositol 3-kinase/Akt pathway in thyroid cancer. Clin Cancer Res 2007, 13:1161-1170.

19. Ji M, Guan H, Gao C, Shi B, Hou P: Highly frequent promoter methylation and PIK3CA amplification in non-small cell lung cancer (NSCLC). BMC Cancer 2011, 11:147.

20. Singh B, Reddy PG, Goberdhan A, Walsh C, Dao S, Ngai I, Chou TC, OCharoenrat $P$, Levine AJ, Rao PH, Stoffel A: p53 regulates cell survival by inhibiting PIK3CA in squamous cell carcinomas. Genes Dev 2002, 16:984-993.

21. Wu G, Xing M, Mambo E, Huang X, Liu J, Guo Z, Chatterjee A, Goldenberg D, Gollin SM, Sukumar S, Trink B, Sidransky D: Somatic mutation and gain of copy number of PIK3CA in human breast cancer. Breast Cancer Res 2005, 7:R609-R616.

22. Fendri A, Khabir A, Mnejja W, Sellami-Boudawara T, Daoud J, Frikha M, Ghorbel A, Gargouri A, Mokdad-Gargouri R: PIK3CA amplification is predictive of poor prognosis in Tunisian patients with nasopharyngeal carcinoma. Cancer Sci 2009, 100:2034-2039.

23. Wu G, Mambo E, Guo Z, Hu S, Huang X, Gollin SM, Trink B, Ladenson PW, Sidransky D, Xing M: Uncommon mutation but common amplifications of the PIK3CA gene in thyroid tumors. J Clin Endocrinol Metab 2005, 90:4688-4693.

24. Engelman JA, Zejnullahu K, Mitsudomi T, Song Y, Hyland C, Park JO, Lindeman N, Gale CM, Zhao X, Christensen J, Kosaka T, Holmes AJ, Rogers AM, Cappuzzo F, Mok T, Lee C, Johnson BE, Cantley LC, Jänne PA: MET amplification leads to gefitinib resistance in lung cancer by activating ERBB3 signaling. Science 2007, 316:1039-1043.

25. Kawano O, Sasaki H, Okuda K, Yukiue H, Yokoyama T, Yano M, Fujii Y: PIK3CA gene amplification in Japanese non-small cell lung cancer. Lung Cancer 2007, 58:159-160.

26. Vivanco I, Sawyers CL: The phosphatidylinositol 3-Kinase AKT pathway in human cancer. Nat Rev Cancer 2002, 2:489-501.

27. Osaki M, Oshimura M, Ito H: PI3K-Akt pathway: its functions and alterations in human cancer. Apoptosis 2004, 9:667-676.

28. Lin $Y$, Jiang $X$, Shen $Y$, Li M, Ma H, Xing M, Lu Y: Frequent mutations and amplifications of the PIK3CA gene in pituitary tumors. Endocr Relat Cancer 2009, 16:301-310.

29. Gray JW, Collins C: Genome changes and gene expression in human solid tumors. Carcinogenesis 2000, 21:443-452.

30. Zhang D, Wang Z, Luo Y, Xu Y, Liu Y, Yang W, Zhang X: Analysis of DNA copy number aberrations by multiple ligation-dependent probe amplification on 50 intestinal type gastric cancers. J Surg Oncol 2011, 103:124-132.

31. Byun DS, Cho K, Ryu BK, Lee MG, Park Jl, Chae KS, Kim HJ, Chi SG: Frequent monoallelic deletion of PTEN and its reciprocal associatioin with PIK3CA amplification in gastric carcinoma. Int J Cancer 2003, 104:318-327.

32. Kantarjian H, Sawyers C, Hochhaus A, Guilhot F, Schiffer C, GambacortiPasserini C, Niederwieser D, Resta D, Capdeville R, Zoellner U, Talpaz M, Druker B, Goldman J, O'Brien SG, Russell N, Fischer T, Ottmann O, Cony- 
Makhoul P, Facon T, Stone R, Miller C, Tallman M, Brown R, Schuster M, Loughran T, Gratwohl A, Mandelli F, Saglio G, Lazzarino M, Russo D, et al: Hematologic and cytogenetic responses to imatinib mesylate in chronic myelogenous leukemia. N Engl J Med 2002, 346:645-652.

33. Lynch TJ, Bell DW, Sordella R, Gurubhagavatula S, Okimoto RA, Brannigan BW, Harris PL, Haserlat SM, Supko JG, Haluska FG, Louis DN, Christiani DC, Settleman J, Haber DA: Activating mutations in the epidermal growth factor receptor underlying responsiveness of nonsmall-cell lung cancer to gefitinib. N Engl J Med 2004, 350:2129-2139.

34. Paez JG, Jänne PA, Lee JC, Tracy S, Greulich H, Gabriel S, Herman P, Kaye FJ, Lindeman N, Boggon TJ, Naoki K, Sasaki H, Fujii Y, Eck MJ, Sellers WR, Johnson BE, Meyerson M: EGFR mutations in lung cancer: correlation with clinical response to gefitinib therapy. Science 2004, 304:1497-1500.

35. Slamon DJ, Leyland-Jones B, Shak S, Fuchs H, Paton V, Bajamonde A, Fleming T, Eiermann W, Wolter J, Pegram M, Baselga J, Norton L: Use of chemotherapy plus a monoclonal antibody against HER2 for metastatic breast cancer that overexpresses HER2. N Engl J Med 2001, 344:783-792.

36. Albert S, Serova M, Dreyer C, Sablin MP, Faivre S, Raymond E: New inhibitors of the mammalian target of rapamycin signaling pathway for cancer. Expert Opin Investig Drugs 2010, 19:919-930.

\section{Pre-publication history}

The pre-publication history for this paper can be accessed here: http://www.biomedcentral.com/1471-2407/12/50/prepub

doi:10.1186/1471-2407-12-50

Cite this article as: Shi et al:: Highly frequent PIK3CA amplification is associated with poor prognosis in gastric cancer. BMC Cancer 2012

\section{Submit your next manuscript to BioMed Central} and take full advantage of:

- Convenient online submission

- Thorough peer review

- No space constraints or color figure charges

- Immediate publication on acceptance

- Inclusion in PubMed, CAS, Scopus and Google Scholar

- Research which is freely available for redistribution

Submit your manuscript at www.biomedcentral.com/submit 